\title{
Redención de la barbarie y el terrorismo*
}

\section{Jon Sobrino \\ Centro de Reflexión Teológica, San Salvador.}

El 11 de septiembre se produjo en Nueva York y Washington un atentado criminal, cruel e injusto, y además insólito. Según los canales de televisión el número de víctimas oscilaría entre 5,000 y 6,000. El hecho es absolutamente condenable sin ambages ni atenuantes.

El gobierno estadounidense, sin embargo, no lo consideró como atentado terrorista aberrante, sino como acto de guerra, y respondió de manera militar contra Alganistán, uno de los tres países más pobres del planeta junto con Somalia y Haití, con bombardeos, destrucción y muerte de civiles. Desde muy pronto se dio la voz de alarma sobre las consecuencias de la guerra: el hambre y el frío podrían producir una Iragedia apocalíptica y llevar a miles de seres humanos a la muerte. Una semana después del comienzo de los bombardeos, el New York Times informaba que 7.5 millones de afganos pronto necesitarían con desesperación un pedazo de pan. UNICEF advertía con preocupación que miles de niños podrían morir en las próximas semanas. Funcionarios de Naciones Unidas pidieron a Estados Unidos suspender los bombardeos para poder socorrer humanitariamente a millones de personas, pero Eslados Unidos no accedió a la petición. El número de refugiados puede llegar a contarse por millones. Algunas voces proféticas comenzaron a hablar de "genocidio silencioso".

Cuál será el luturo de Afganistán como nación es difícil saberlo. Pero más importante es preguntarse por el futuro humano, que, por ahora, es muy sombrío. A los males que hemos mencionado, en el párrafo anterior, añadamos solaınente

* El presente artículo es la ampliación de una conlerencia pronunciada en la UniversiJad Centroamericana "José Simeón Cañas" el 14 de noviembre, 2001. 
que centenares de prisioneros, maniatados por cierto, fucron fusilados en el fuerte de Qala-e-Jahngi, a pocos kilómetros de Mazar-e-Charif, por la Alianza del norte. Instituciones de derechos humanos dan la cifra de 600 ejecuciones sumarias en un solo día. Hasta el presidente Bush tuvo que pedir desde Washington que se respetasen los derechos humanos.

Lo que está en juego, en definitiva, es el futuro de lo "humano", ante todo de los millones de afganos y de los pucblos circundantes, en Asia, pero también, lo sepan o no, está en juego lo humano de los estadounidenses y sus aliados europeos. Sobre lo humano y su futuro queremos rellexionar en este artículo. Pero antes hagamos unas aclaraciones previas para explicar los términos que aparecen en el título.

1. Hablamos de "barbarie" por ser un término genérico más abarcador que el de "tстоrismo". Y lo hacemos, porque, aunque es necesario aquilatar conceptos -Naciones Unidas y la Unión Europea buscan definir qué es "Ierrorismo"hoy hay un grave peligro de reducir "barbarie" a "terrorismo", y de reducir terrorismo a "lo ocurrido en las torres". La implicación es obvia: si se dice que lo de Nueva York es "ierrorismo" y que lo de Afganistán es "guerra", sin relacionar ćsta en absoluto con ningún tipo de "barbarie", entonces, Estados Unidos ya ha ganado la batalla de la delinición, con lo cual pretende ganar de anternano la balalla ética, y poder presentarse asi como país defensor del bien. El "terrorismo" scría abominable - y lo cs-, y tiene que ser combatido hasta su desaparición, parecc decir Estados Unidos. Pero la "guerta" sería otra cosa. Puede llegar a ser justa, noble, salvadora de la humanidad. (El gobierno de Israel ha aprendido muy bien la lección, y describe lo que allí ocurre como "guerra" contra el "Icrrorismo" palcstino.)

Para cvilar que sc llegue a esa conclusión aun antes de analizar la realidad de los hechos. hablamos de "barbarie" como conceplo lundamental para comprender lo que está ocurriendo. Incluye tanto lo de Nueva York como lo de Alganistán. Su gravedad. cuantitativa y cualitativa, provendrá de la realidad, no del ićrmino con que se la describa. Pero no sc está procediendo así. Estos tres meses hemos visto - y padecido- las miles de veces que la $C N N$ ha usado el término "Icrorismo" para describir cl alentado a las torres, pero no ha usado ni sicjuicra a modo de sospecha- términos como "crueldad masiva", "matanaas" de inocentes $\mathrm{c}$ indelensos, "tragedia humana", para describir las acciones de los aljados y sus consecuencias.

2. Hay que liberar de la barbaric, superarla, es evidente, pero en el tílulo se dice que. además, hay que redimirla, lo cual no es exactamente lo mismo. La supcración de la barbaric supone eliminarla, haciendo uso de todos los medios clicaces y éticos, combatiéndola, por así decirlo, "desde luera" de ella misma. Pcro la "redención" de la barbarie supone, además, erradicar sus raíces últimas, lo cual no nuede hacerse sin "carear" con el neso de la realidad. es decir. com- 
hatiéndola "desde dentro". Es ésta una importante intuición de la tradición bíblica: no hay redención sin "cargar" con el pecado, con la barbaric, la injusticia. $Y$ así lo confirma la historia, desde Jesús de Nazaret hasta Gandhi, Martin Luther King. Monseñor Romero...

3. Nuestro análisis no va a ser doctrinal: qué es barbarie, terrorismo, guerra sánta. guerra jusla, sino una modesta reflexión desde una perspectiva humana y cristiana, profética y utópica. Nueva York y Afganistán son un hecho real e inlejpelante. Pero son también un hecho altamente simbólico, y como todo símbolo, en las palabras tantas veces citadas de Paul Ricoeur, "invita a pensar". Y cuando cl símbolo es la cruz de seres humanos, enlonces, "mueve a cambiar el modo de pensar, invila a la conversón"', como precisa Jürgen Moltmann, en el prólogo de su libro El Dios crucificado. Nueva York y Alganislán dan que pensar y mueven a tener que habérnoslas con nosotros mismos.

4. Sobre este inmenso símbolo de nuestro mundo queremos reflexionar desde El Salvador, y bien saben los teólogos la importancia decisiva del lugar (no como un mero ubi categorial -espacio geográfico-, sino como un quid sustancial -realidad de injusta pobreza y violenta opresión) para captar la realidad de una manera o de otra. Por lo que toca al tema de cste artículo esto quiere decir tres cosas.

La primera es que en El Salvador tenemos experiencia directa, masiva, prolongada y sumamente cruel de barbarie y de terrorismo, sobre todo del lado gubernamental. No hablamos de oídas.

La segunda es que conocemos bien un hecho innegable, importante para siluarnos en la actual crisis: el gobierno de Eslados Unidos innumerables veces ha invadido o intervenido diplomática, política, militarmente y con golpes de Estado, en muchos países, y ha apoyado a regímenes dictatoriales, violadores de los derechos humanos, en varias ocasiones crueles y asesinos. Lo conocemos de cerca aquí en El Salvador —en la cercana Nicaragua, Guatemala, y en la guerra de Panamá, en 1989. También el gobierno de Estados Unidos es clara y masivamente responsable de prácticas de barbarie y políticas terroristas.

La tercera aclaración es de otra índole, y es lo más novedoso y especílico que tenemos que ofrecer desde El Salvador al hablar de barbarie y terrorismo. Hemos conocido un gran número de personas, muchas de ellas cristianas, seguidores y seguidoras de Jesús, que han buscado "superar", y además, "redimir" la barbarie, el Icrrorismo, la guerra, la violencia, en definitiva, la injusticia, luchando contra cllo y cargando con ello. Muchos son, y entre ellos están, de manera insigne, los "Inártires" — con los que el mundo occidental no sabe qué hacer-, desde Monseñor Romero hasta los campesinos de El Mozote. Tienen mucho que decir sobre

1. El Dios crucificado, Salamanca, 1977, p. 16. 
lo quic cs barbaric y terrorismo. sobre quiénes son sus víctimas y quiénes son sus responsables principales. y también sobre cómo combatirlos y redimirlos.

A continuación, en forma de breves proposiciones, queremos rellexionar sobre realidades humanas fundamentales, a las que, por presencia o ausencia, remite la crisis actual: la ultimidad del sufrimiento y de la compasión, la voluntad de verdad y de utopía, la realidad de Dios y el uso que de él se hace en los confliclos. la redención que proviene de las víclimas.

Las rellexiones están hechas desde una perspectiva cristiana. comprensible, esperarnos, para cualquiera, aunque no están formuladas en lenguaje explícitamente teológico. Su linalidad última no es doctrinal. sino existencial: ayudar a "habérnoslas con Nueva York y Alganistán", "habérnoslas con lo inhumano y lo humano".

\section{La ultimidad de lo humano: sufrimiento y compasión}

Primera proposición. La barbarie y el tertorismo nos cuestionan sobre lo que cs último para los seres humanos, y nos interpelan, sin posible escapatoria, a dar una respuesta. Eso "último" es el sufrimiento de las víctimas. Y la reacción "última" es la com-pasión hacia cllas. con-sufrir con ellas y vivir y desvivirsc por eliminar su sufrimiento.

Lo que acabamos de decir pudiera parecer obvio, en teoría al menos, pero no lo es. Empecemos con cl 11 de septiembre. En Eslados Unidos -y en otras partes- muchos fueron alectados por el sufrimiento de las víclimas, pero no todos. Otros pudieron incluso alegrarse, y otros pudieron reaccionar con una especie de rellexión sapiencial: "merecido lo tienen", "ahora experimentan ellos lo que han hecho sufirir a otros", "que se pregunten por qué ha podido suceder lal harbarie". Quienes así hablan no son monstruos, ni profieren absurdos, pues algo hay de racionalidad en lo que dicen. Pero precisamente por eso, la constatación nos lleva a formular la siguiente tesis: aun sin maldad especial, puede no ser nada lácil dejarse alectar por el sufrimiento ajeno, aunque éste sea evidente y cruel.

Y si lo dicho es verdad ante lo ocurrido en las torres es verdad muchísimo mayor ante lo ocurrido en Afganistán: bombardeos, muertes de civiles, niños hambricnlos, mujeres huyendo; ante lo ocurrido en Irak y las 100,000 víctimas de los bombardeos aliados; ante lo que ocurre a las víclimas del VIH/sida que no tienen los 10.000 a 15,000 dólares anuales para conseguir retrovirales (se calcula que sólo 400,000 de los 36 millones de afectados pueden conseguirlo); ante los 1,300 millones de pobres que tienen que vivir diariamente con menos de un dólar...

Las razones estructurales para esa insensibilidad ante el sufrimiento de las víctimas -aun sin tener en cuenta el componente de limitación y maldad huma- 
na de los individuos-, en el caso de Nueva York y Afganistán, pueden ser varias: por una parte, una sensibilidad generalizada, más o menos justificada, de hostilidad y deseos de revancha, $y$, por otra, ignorancia $-y$ aun despreciogeneralizados de lo que ocurre a pueblos tenidos como inferiores, como si fuesen metafísicamente minusválidos. El sufrimiento de las víctimas del tercer mundo no hace sufrir mucho. No hay un dolor generalizado en el primer mundo anle la mucric de los pobres en Afganistán, la destrucción de sus viviendas y la tragedia de los refugiados. Tampoco lo hubo ante los cuerpos torturados y los niños robados durante la represión, en El Salvador.

Estamos, pues, ante una especie de "existencial inmunizante contra el sufrimiento de las víctimas", que permea nuestra mal llamada civilización. El mundo actual cuenta con los medios para mostrar ese sufrimiento (reportajes televisivos, periodísticos, internet) y hacer que nos interpele, pero cuenta también con los medios para quitarle mordiente y ahogar la interpelación sin sentimiento de culpa (la industria del entretenimiento, la música, el deporte...). Con excepciones, lo segundo prevalece sobre lo primero. Al constatar esta inmunización ante el sufrimiento de las víctimas, no exigimos ninguna imposibilidad psicológica: dejarse alcctar por el ingente sufrimiento existente en el mundo, en sus diversas formas. El asunto no es primariamente de psicología, ni siquiera de ética, sino de antropología lundamental: preguntarnos por lo humano. No podemos ser humanos sin remilitnos a lo que es último en la realidad. Y esto último es el sufrimiento de las víctimas.

Así lo vio Monseñor Romero. En una entrevista que dio a El Diario de Caracas, el 19 de marzo de 1980, poco antes de ser asesinado y en plena crisis del país, le preguntaron qué se podía hacer ante el sufrimiento del pueblo salvadoreño. Enumeró una serie de acciones y terminó con estas palabras: "que no se olviden que somos hombres y aquí están muriendo, huyendo, refugiándose en las montañas"?.

Ante la tragedia (Manhattan, Afganistán, la injusta pobreza y las innumerables guerras que globalizan el planeta, prácticamente todas en el tercer mundo), lo primero que hay que hacer es "no olvidar que son hombres", que estamos ante seres humanos. Por eso, como decía L. Bolfi, después del atentado en Nueva York, "no hay que preguntar por quién doblan las campanas"”. No hay que preguntar si el que sufre, la víctima, y el que ayuda, el samaritano, es amigo o enemigo. Sulrimiento y compasión no pueden ser vistos desde tal o cual etnia o rcligión, causa o ideología. Ni siquiera hay que preguntarse si en la otra vida se repara el sulirimiento y se premia la compasión. En Manhattan y Afganistán, y

2. J. Sobrino. 1. Martín-Baro, R. Cardenal (eds.), La voz de los $\sin$ voz. San Salvador, 1980. p. 439.

3. "Manifiesto por la concordia y por la paz". Carta a las Iglesias 481-482, 1-30 de scptiembre. 2001. p. 7 
en la República Democrálica del Congo estamos ante muertos, heridos, desaparecidos, relugiados, desprotegidos, desesperados. Estamos ante el sufrimiento no dc americanos, asiálicos o alricanos, sino ante el sufrimiento de seres humanos.

Y eslamos lambién -sólo pequeños gestos son conocidos- ante la compasión: en Estados Unidos, ayuda heroica a las víctimas, familiares que no quieren venganza ni guerra, una congresista aliroamericana que vola en el Congreso -el único voto- en contra de la guerra. Cómo se defiende la vida y la dignidad en Alganistán es más difícil saberlo desde aquí, pero recuérdese la santidad primordial y la solidaridad, en situación de espantosa pobreza, como lo sabemos aquí muy bien del tiempo de represión y guerra. Y compasión hay también en el claınor de Mary Robinson, alta comisionada de Naciones Unidas: que cesen los hombardeos "para hacer posible que lleguen alimentos y cobijas a millones de alganos" en el invierno que se avecina.

No se puede relativizar el sufrimiento, ni la exigencia de compasión. No se pucde ofender al ser humano justificando la barbarie: "Ellos son los infieles", por un lado. "Nosotros somos los mejores, los más poderosos", por otro. Sufrimiento y compasión relativizan - ponen en su lugar-cualquier otra cosa que se haga pasar por última: iglesias y religiones, pero también - tan olvidado- socialismos antes, democracias occidentales ahora. La gran pregunta es, en delinitiva: ¿duelen e intcrpelan las víctimas o no? ¿Duele e interpela el sufrimiento o no? ¿Fascina e interpela la compasión o no? Ahí se dividen los espíritus y se decide el futuro de la familia humana.

En el mundo en que vivimos hay personas, grupos, algunas instituciones, que se dejan afectar por el sufrimiento y la compasión. Pero no suele ocurrir cnire los poderes que lo configuran. La compasión es tolerada, alabada incluso, micntras no se torne en lucha por la justicia. Y el sufrimiento - sobre todo el del tercer mundo- es arrumbado a una lejanía sin semblante. Eso ocurre en la práctica, pero está presente, tácitamente, incluso en la teoría.

Por lo que toca a las sociedades democráticas, digamos que buenas son "la libertad, igualdad y lraternidad". Pero no se acaba de ver, ni siquiera teóricamente, que se propicien como respuesta adecuada al ingente sufrimiento del mundo. $Y$ es que en el centro no está el pobre -el sufriente-, sino el ciudadano4. No es de

4. Recordemos que en el origen de los derechos humanos, hace dos siglos. no aparecían los pobres, ni menos se hacía de ellos el centro de esos derechos. En su comienzos esos derechos - nuevos- tenían a la vista a los freemen ingleses, a los hombres blancos de Virginia, a los burgueses franceses, pero no a todos, ni siquiera a los que convivían con ellos: campesinos ingleses o franceses, negros y esclavos norteamericanos, aunque teóricamente no se les negase el carácter de "seres humanos" - en lo cual sí hubo un avance teórico. Algo han cambiado las cosas, por supuesto. pero no al punto de revertir la "parcialidad" histórica de las sociedades democráticas en favor del poderoso y convertirla - como ocurre en la tradición bíblica- en "parcialidad" hacia el débil y el pobre. 
extrañar. entonces, que a las democracias occidentales les falta compasión y miscricordia.

Por lo que toca a la Iglesia, a lo largo de su historia, ha intentado aliviar cl sulrimiento, aunque no sea más que a través de la beneficencia, mejor o peor entendida. Pero la "ultimidad del sufrimiento", incluso teóricamente, fue desapareciendo. Fue sustituida desde muy pronto por la "ultimidad de la culpa". Así explica J. B. Melz con precisión ese cambio epocal y sus consecuencias:

El cristianismo, de una religión sensible al sufrimiento, se convirtió cada vez Inás en una religión sensible al pecado. Su mirada no se dirigió primero al sulirimiento de la criatura, sino a su culpa. Esto entumecía la sensibilidad por cl sulrimiento ajeno y oscurecía la visión biblica de la justicia de Dios que. después de Jesús, había de valer para toda hambre y seds.

En la aclualidad, con excepciones, como algunas iglesias lieles a Medellín en el Icrcer mundo y grupos de solidaridad en el primero, no parece que la Iglesia otorgue ultimidad al sufrimiento de las víclimas, viva y se desviva por ellas.

\section{***}

Terminemos con una sencilla reПexión cristiana. El sufrimiento y la compasión son los que nos posibilitan ser reales - superar el docetismo, que se dice en teología-, ser simplemente humanos, y así vivir ya como salvados. Sin dejase alectar por el sulrimiento y sin reaccionar con compasión falla lo básico, y en esto consiste, a mi entender, la crisis fundamental de nuestro tiempo. Sus expresiones son variadas: desde los terrorismos hasla las guerras, desde la amenaza nuclear de hace unos años hasta la destrucción de la madre naturaleza, desde excluir de la vida a buena parte de la humanidad hasta la proliferación del sin sentido de pertenecer a una "especie" que no acaba de Ilegar a ser "familia" humana. Pero lo que está detrás de todo es la "inmunización" ante el sulrimiento de las víclimas y la "incapacidad" de compasión. Sin esto, sólo queda el egoísmo, personal y, sobre todo, social, burdo o sutil.

Sin la centralidad del sufrimiento y de la compasión, no se puede ser humano. La admiración es lo que mueve a conocer, decía Aristóteles - y bien está. Pero hay una admiración específica que pone al conocimiento en una dirección humana. "El sufrimiento precede al pensamiento", decía Feuerbach. Y después del desencanto con la modernidad, Adorno pedía volver al sufrimiento como algo central. "La necesidad de dejar hablar al sufrimiento es condición de toda verdad".

5. "Hacia una cristología después de Auschwitz", Selecciones de Teología 158 (2001), p. 114 . 
Y en definitiva, para ser humanos, es central la compasión. El sufrimiento de la víclima es lo que puede descentrar al ser humano y poner en el centro el amor. ¿Quién cumple todos los mandamientos? Es decir, ¿quién es verdaderamente humano? El samaritano. "Ante la víctima, movido a compasión, vendó sus heridas" (Lc 10. 33s). He ahí al ser humano cabal, no por ser "religioso", ni "demócrala", ni "cl mejor", sino por moverse a compasión.

\section{La voluntad de verdad: la verdad mayor}

Segunda proposición. No es lo mismo liberlad de expresión que voluntad de verdad. Esta última no se ha hecho presente, con excepciones, en Estados Unidos, sino que ha habido silencios, tergiversación, encubrimiento, amnesia histórica. Todo ello deshumaniza y en nada ayuda a la superación de la barbarie y del terrorismo. Lo que humaniza es la voluntad de verdad.

En las democracias occidentales se habla mucho de la liberıd de expresión, pero la voluntad de verdad es otra cosa. La barbarie de las torres es el acto terrorista más publicitado en la historia de la humanidad (la destrucción de Afganistán no sc le compara ni de lejos, ni menos los 80,000 muertos mensuales de la guerra en la República Democrática del Congo, en los últimos dos años), pero el discurso olicial y los medios no ha comunicado toda la verdad, ni lo más hondo de la verdad, en los hechos y menos en las causas. $Y$ es que no es 10 mismo libertad de expresión - que cuesta dinero-que voluntad de verdad -que sólo requiere honradez. lucidez y fortaleza.

Para empezar, acerca de la barbarie de las torres se han comunicado verdades a medias. Según la Cruz Roja de Estados Unidos el número de víctimas lue de 2.553. y según la Associated Press de 2,625, es decir, menos de la milad de las ciliras estimadas en los medios. Y por lo que toca a la interpretación del hecho. cl World Trade Center no era sólo un símbolo del poder económico, sino lambićn, según The Guardian (2 de noviembre de 2001), un centro de la CIA y de los scrvicios secretos. Fuc, pues, un ataque a un objetivo militar-financiero (el caso (lel Pentágono es claro). "En resumen, los actos del II de sepliembre tienen dos caras: la tragedia humana y el heroísmo personal que $C N N$ nos presentó, y $\mathrm{cl}$ conllicto de poder económico-político entre el imperio de Estados Unidos y sus adversarios en cl lercer mundo"h.

Nada de esio niega que el ataque terrorista no haya sido abominable y no deba ser condenado. Pero ilumina que no es lo mismo libertad de expresión y voluntad de comunicar verdad. En el mundo de los pobres. esto se ve con toda clariclad: los que lienen la verdad y quieren decirla no tienen voz. y los que lienen mucha vo\% no están interesados en la verdad. ni inenos en querer hacerla

6. Los clatos están tomados de "El 11 de septiembre más allá de la tragedia humana", Peigina de Pelras. I0 de noviembre de 2001. 
pública. Más aún, en el mundo occidental, el enorgullecerse de la libertad de expresión y ver en ello un gran logro de la democracia puede ser - y a veces es - la coartada para encubrir la falta de voluntad de verdad. Además, en tiempos de guerra, la libertad de expresión simplemente deja de existir, y no sólo no se comunica verdad, sino mentira. "Los medios informan lo que les dicen los gobiernos, y eso lo tienen en común Estados Unidos y los talibanes afganos"?

En conclusión, sólo la voluntad de verdad, no la libertad de expresión sin aquéIla. garantiza la "verdad mayor", es decir, la verdad. Vearnos algunas dimensiones de esa verdad mayor, que han sido silenciadas, encubiertas o manipuladas.

a) Es verdad que existe el terrorismo, pero la verdad mayor es que las potencias han usado el terror, cuando les ha venido en gana: en Auschwitz, Dresden c Hiroschima, en la Unión soviélica (Gulag), hace años. Por lo que loca a Estados Unidos, en América Latina, en los setenta y ochenta, en Irak y Sudán, más recientemente, en la actualidad, a través de Ires países, Uganda, Rwanda y Burundi (para obtener control del coltán), en la República Democrática del Congo. interviene "sin miramientos" con terrorismo cuando hace falta. Y además con conciencia de que su "destino manifiesto" (expresión acuñada en 1845 por el periodista John O'Sullivan para justilicar la anexión de casi medio México) es imponer su voluntad a otros países para el bien de éslos. Simón Bolívar lo captó muy bien: "Los Estados Unidos parecen destinados por la Providencia a plagar a América de iniserias en nombre de la libertad"

b) Es verdad, y la verdad mayor, que existe y persiste olro lipo de terrorismo - en delīnitiva más originario, y por ello más peligroso, y más cruel, porque mata a muchísima más gente- de cuya esencia "aterradora" poco sc habla: el terrorismo del hambre y la pobreza, el que causa millones de excluidos y relugiados, el que arrumba al sida a la ignorancia y al desprecio. La conclusión es que millones de seres humanos viven hoy "atertorizados", no por acciones concrelas violentas. sino por estructuras inhumanas, violadoras de lo humano Esic tipo de harbarie sólo mínimamente se da a conocer de forma olicial y no se organizan caınpañas para comunicarlo de lorma masiva.

Menos se dan a conocer sus causas últimas, que, en buena parte. están en los países que defienden la libertad de expresión. La harbarie se da a conocer en proporción inversa a su magnitud y prolundidad: de manera apabullante, en el caso de unas 3.000 víctimas; marginalmente, en el caso de miles de millones de víclimas de guerras, violencia y hambre.

7. "Guerra. Para el jesuita Pungente la información de los medios es unidireccional". 29 de noviembre. internet. John Pungente. S. J. es director del Jesuil Communicalion Project deToronio.

8. Citado en J. I. González Faus, "De talibanes y 1alibushes". La Vanguarriá. 29 de noviembre. 200 I. 
Contra esto se han levantado varias voces cualificadas estos días. Citemos sólo dos de ellas. Varios premios nobel de la paz escribieron al secretario de Naciones Unidas. Después de rechazar la opción por la guerra que acababa de comenzar, dicen:

La lucha debe librarse contra la bomba silenciosa del hambre, la pobreza y la exclusión social, que representan una situación de injusticia estructural política y económica que hoy sufren la mayoría de los pueblos del mundo?.

Un grupo de veinticinco obispos católicos y pastores evangélicos, brasileños y mexicanos, constata la situación trágica de continentes enteros, condena las políticas del neoliberalismo y la "indiferencia internacional". Y concluye:

Sin la superación de las tensiones provocadas por la exclusión y marginación de grandes mayorías; sin el compromiso concertado y sincero para disminuir las desigualdades intemacionales, para eliminar el hambre, el racismo, la discriminación contra las mujeres y minorías étnicas y religiosas, para cancelar o reducir la deuda de los países pobres y para limilar la destrucción y los daños ambientales, difícilmente se gestarán las condiciones de una paz duradera ${ }^{10}$.

c) También es una verdad mayor que occidente controla celosamente "la defínición" de lo que es terrorismo, de quiénes son terroristas y de qué hay que hacer con ellos, con lo cual, al tildar un hecho de "terrorista", ya se prejuzga sobre qué se puede y hay que hacer con sus autores. El acceso a la verdad es negado ahora de forma cualitativa, y por eso, más grave.

Reservarse la definición de las cosas más importantes y sacar ventajas de ello es algo que occidente hace con frecuencia. "El ser humano es la medida de todas las cosas", decían los griegos, y la traducción eficaz, en la actualidad, es: "occidente - sobre todo Estados Unidos- y sus democracias son la medida de Iodas las cosas". Son la medida de la verdad. Y no en cosas baladíes, sino en las fundamentales. Dicen e imponen qué es "progreso" y qué es "felicidad", qué es "bondad" y qué es "maldad", qué es "políticamente correclo" y qué es "políticamente incorrecto". Quieren introyectar, en defínitiva, la delínición de qué es lo "humano".

Como en olros ámbitos de la realidad, también convierten en propiedad privada la defínición de las realidades fundamentales de la vida. Y este dinamismo privatizante, como el que generan casi todas las propiedades privadas, priva a otros de poder decir su palabra, en este caso, sobre lo qué es terrorismo, sobre todo a los millones de víctimas que producen los diferentes terrorismos, arriba

9. Carla del 8 de octubre de 2001. Firman Maired Corrigan Maguire, Adolfo Pérez Esquivel y Rigoberta Menchú Tum.

10. "Clamor de los pueblos por la justicia, la solidaridad y la paz". Carta a las Iglesias 484.16-3i de oclubre, 2001 , p. 10. 
mencionados, en todo el planeta. A través de la imagen y de la palabra, no sólo nos ofrecen una visión de cómo es la realidad, sino que imponen la forma de cómo comprenderla. "El poderoso aparato mediático globalizado ha transmitido los cánones del pensamiento necesario y correcto""'. Y to hace sin pudor, porque es "consciente de que es casi imposible llevarles la contraria"'2.

En el caso de la definición de terrorismo ${ }^{13}$-independientemente de las voluntades de quienes con sinceridad analizan su esencia formal- lo más pernicioso es que el terrorismo ha quedado historizado como patrimonio de los débi. les. En la conceptualización convencional, "terrorismo" y "débiles" son correlalivos. Noam Chomsky aduce la posibilidad de que así sean las cosas y sobre todo explicita (desenmascara) la razón por la cual son así. "El terrorismo es considerado arma de los débiles porque los fuertes controlan los sistemas doctrinarios y su terror no cuenta como terror"/4. La consecuencia es terrible: hagan lo que hagan los fuertes - que ahora son sobre todo occidente y sus democracias-, aunque usen de la violencia (militar, física, policial, ideológica), eso no es, por definición, terrorismo. Será olra cosa, pero no terrorismo, no puede serlo. De ahi que, si en bombardeos mueren civiles -recuérdense los 100,000 en Irakeso son "daños colaterales" de la guerra, que no pertenecen a su susrancia, sino a sus accidemtes. A priori no puede ser comprendido como terrorismo"s.

Es cierto que existen terroristas de a pie - a quienes cuadraría de antemano la delinición-, que son mostrados en televisión, malencarados. Pero la verdad mayor es que también existen los terroristas de Estado - muchos los ha habido en cl siglo $\mathrm{XX}$-, mejor vestidos y más poderosos, y en muchos ámbitos del poder: político, militar, económico. Si no hay voluntad de verdad para aceptar esic hecho, se mantiene y crece la deshumanización. Y en cllo, cl terrorismo de los de a pie siempre encontrará una excusa, que, por macabro que sea el decirlo, será comprensible e históricamente inevitable hasta cierto punto.

11. Manuel Vázquez Montałbán. Prólogo, en Susan Gcorge, Informe Lugano, Barcelona, 200I. p. 10.

12. Ibid.

13. Por mucho que haya que alinar la delinición, por terrorismo se puede entender una acción con intención de "alertorizar", es decir. de lograr inlundir iniedo como móvil para ohtener unos comportamientos determinados. Las acciones pueden consistir en matar o herir personas, y, o destruir o dañar bienes de valor, normalmente con crueldad.

14. "Injusticia inlïnila", discurso pronunciado en el Massachuselts Institute of Technology, 18 de oclubre de 2001 , p. 6.

15. A csı hipocresía hay quc añadir otra bien conocida, pero que se mantiene oculta: los unétodos usados por los servicios de inteligencia, militares y civiles, en Argelia. por Ios franceses, en América Latina, por militares formados en la Escuela de las Américas... Sca cual lucre la delínición técnica a la que se lleguc. esos métodos son evidentcmente inhuinanos. y sc han usado. además de para conseguir resultados inmediatos. usando a las víctimas, para generar un ambiente de terror que paralice no sólo inoviinienıos subversivos, sino el ejercicio de los derechos humanos. 
d) También es verdad mayor que se ocultan las grandes decisiones que se toman sobre la suerte del planeta y el por qué. En el caso de la guerra en Afganistán no se dice, obviamente, toda la verdad de las razones, que, además, pueden ir cambiando. Pero la razón no es sólo la seguridad militar, sino que hay otras razones más lundamentales y de más largo alcance sobre las cuales no se habla, ni se dice la verdad. El llamado "derecho a la información" corre muchas veces la misina suerte que la "libertad de expresión". A ambas cosas se les ponen línites cuantitutivos — cuánto se puede decir y exigir-y cualitativos —qué se puede decir y exigir.

Sobre el por qué de la guerra contra Afganistán, en el inicio estuvo, ciertamentc. la necesidad de reaccionar con prepotencia ante la humillación y de mostrar lucrza y poder"t. El blanco inmediato era Bin Laden, pero la finalidad de londo bien pudiera haber sido otra. "La evidencia sobre la culpabilidad de Osama Bin Laden no interesa a Estados Unidos; su objetivo es establecer su derecho a actuar como y cuando le dé la gana y fijar con claridad su credibilidad como matón global"'?. En cualquier caso, siempre hay que considerar la necesidad de controlar el petróleo de la región y la facilidad para poder acabar con Irak.

Terminemos estas reflexiones sobre la verdad mayor. Se ha repelido que el II de septiembre representa una fecha clave en la historia de nuestra época, un antes y un después. Lo que hay que preguntarse es por qué es una fecha clave. En nuestra opinión, una de las razones es que ha abierto una ventana a la verdad global de este mundo y ha mostrado su engaño fundamental, la fragilidad —en muchísimos casos hipocresía - de lo humano de su progreso.

Sc ha proclamado que "ha llegado el lin de la historia", como la buena noticia escatológica y universal. Con la "globalización" habría llegado o estaba por llegar el reino de Dios en forma cconómica (el neoliberalismo), en forma política (las democracias occidentales) y en forma cultural (puede pensarse en la homogencización de una civilización montada sobre la inflación de la televisión. series. música, mundiales y olimpíadas multimillonarias). El 11 de sepliembre impuso un silencio clocuente, y alguien preguntaba con ironía "qué había pasado con la aldea global". La verdad mayor no es la de la globalización, sino otra'.

Cada día experimentamos con más fuerza la contradicción entre un régimen inundial fuera de todo control democrático y con un extraordinario poder

16. Rigoberta Menchú escribió al presidente Bush: "Quienes estamos hartos de poner los muertos en guerras ajenas. no podemos compartir la arrogancia de su infalibilidad ni el camino unívoco al que Ud. desea empujarnos cuando afirma que 'Todas las naciones en codas las regiones deben tomar ahora una decisión: o están con nosotros o están con los terroristas'".

17. Noan Chomsky, op. cit. p. 1.

18. Véase. J. Sobrino. F. Wilfred, La globalización y sus victimas, Concilium, número monográfico. 293 (noviembre 200I). 
para delender los intereses económicos, políticos y culturales de un pequeño liagmento de la humanidad y la pervivencia de un cierto debate y juego político democrático dentro del marco político... con cada vez menos poder para incidir en las cuestiones más vitales ${ }^{19}$.

¿Se revertirá esta contradicción? Lo más probable es que se seguirá predicando la buena noticia, y pronto se volverá a proclanar con el entusiasmo anterior al II de septicmbre. Se dirá que "hemos ganado". Pero lodavía no se ha explicado qué significa ganar, ni en los detalles — lo cual es comprensible-. ni en lo lundamental -lo cual es más grave. Ni se explica qué de bueno liene - para la humanidad- "ganar". Tras las palabras de los que ganan hay un silencio mayor. que habla mucho más elocuentemente de lo que es hoy nuestro mundo. silencio que no desaparece con partes de gucrra que anuncian con comedido triunlalismo las hazañas de la tecnología y que han evadido con calculada ignorancia los bombardeos a civiles, personas e instalaciones, hambre, refugiados, terrorismo de los vencedores...

Sc habla del "nuevo orden mundial", pero no se dice qué es ese orden, si es "la huena disposición de las cosas en el mundo", o si es la redisıribución geográlica, cconómica. militar y política del planeta entre los de siempre para mantener el buen vivir $y$. después del susto, para gozar del buen vivir con mayor seguridad. La pregunta que ahora se hace: "cómo compaginar libertad y seguridlad". expresa que se quiere "seguir con lo mismo". No se piensa realmente en algo nuevo, en un nuevo quicio sobre el cual, por fin, el mundo pueda girar de una lorma hurnana. Este quicio no es el poder, en ninguna de sus formas, sino las víclimas, las que. si se las pone en el centro, pueden humanizar a esle mundo.

La verdad mayor es que las llamadas "luerzas del bien" no miran bien al resto del mundo (ni a los aliados por libre voluntad o a la luerza, ni a los otros, a los adversarios, a los enemigos), no piensan bien, no escuchan bien a otros, a veces más sabios y prudentes, en cosas importantes (Bush padre tampoco escuchó a Juan Pablo II anles de hombardear a Irak), no saben reaccionar bien. Ni siquiera saben contestar con honradez a la pregunta fundamental: ¿qué queremos? ¿Queremos arcos de triunfo y coronas de laurel como antes? ¿O queremos un abrazo liatcino?

Don Pedro Casaldáliga, profeta y pocta, dice que las cosas no pueden seguir assí, y escribió a san Francisco de Asís unas bellas rimas, "en lorma de desahogo", como él dice. Pensando en el nuevo orden mundial de que ahora se habla, cito sólo una de ellas.

Compadre Francisco,

el mundo es tan viejo

19. J. Corominas. “Cancelar el pasado? Tolerancia y oscurantismo en la sociedad mundial". ECA 629 (2001), 241 s. 
que habrá que hacer otro

para verlo nuevo.

Ignacio Ellacuría, profela y pensador, lo dijo de otra manera, con vigor inigualable, lo cual nadie discutirá, y, en mi opinión, también con inigualable rigor, lo cual podrá scr discutido. Meses antes de su asesinato, en una conferencia sobre el quinto centenario, teniendo en cuenta, el mundo universo, dijo:

Desde mi punto de vista - y esto puede ser algo profético y paradójico a la vez- Estados Unidos está mucho peor que América Latina. Porque Estados Unidos tiene una solución, pero en mi opinión, es una mala solución, tanto para ellos corno para el mundo en general. En cambio, en América Latina no hay soluciones, sólo problemas; pero por más doloroso que sea, es mejor tener problemas que tener una mala solución para el futuro de la historia ${ }^{20}$.

Las palabras son audaces y utópicas, pero son fruto de voluntad de verdad y ponen al descubierto la verdad mayor. El 11 de septiembre (y lo que está ocurriendo tres ineses después en Palestina) le dan la razón: el gigante -ése que va a traer salvación- tiene una mala solución. Y tiene los pies de barro.

\section{***}

¿Qué decir sobre la verdad desde la fe cristiana? "La cólera de Dios se ha revelado contra los que oprimen la verdad con la injusticia" (Rom 1,18 ). Las consecuencias son el oscurecimiento del corazón, lo último del ser humano, quien queda entregado a todas las aberraciones, a la deshumanización. Los poderosos, sin embargo, quieren mantener la verdad oprimida, para que la verdad de la realidad no salga a la luz. Y es que, como mantiene centralmente la tradjción cristiana, el mal siempre tiende a encubrirse, a hacerse pasar por lo que no cs. El maligno es asesino y mentiroso, dice el evangelio de Juan, y por ese orden. Depreda, oprime, da muerte, y luego lo oculta.

Jesús, por el contrario, es proclamado camino, verdad y vida. La verdad "encamina" y "vivifica" a los seres humanos. Y lucha también contra la mentira. Lo han hecho los grandes en nuestros tiempos (Romero y Gerardi). En el contexto actual, bueno será recordar a Martin Luther King. Un año antes de ser asesinado, protestando contra la guerra de Vietnam, dijo: "Ha llegado el momento en que cl silencio es traición".

Para no caer en traición, no basta hacer uso de la libertad de expresión y gloriarse de ella, sino poner a producir la voluntad de verdad.

20. "Quinto centenario de América Latina. ¿Descubrimiento o encubrimiento?”, Revista Latinoamericana de Teologia 21 (1990) 277. 


\section{La utopía de la reconciliación: "Manhattan y El Salvador se hermanan"}

Tercera proposición. En medio de la barbarie y el terrorismo ha prevalecido la prepotencia sobre la comprensión, la destrucción sobre la reconciliación, el pragmatismo egoísta sobre la utopía. Pero si ésta desaparece del todo, no es posible lo humano. Pequeños signos de utopía la mantienen con vida, $y$, con ella, la esperanza.

La guerra de Estados Unidos -constituyéndose a la vez en juez y partecontra Alganistán, país soberano, no es una "guerra justa", pues no cumple con las condiciones exigidas por la teoría tradicional para ello, y contradice teorías actuales de que hoy no puede haber ninguna guerra justa, dados los males que producen con la nueva tecnología militar, dadas las posibilidades de presiones no bélicas y la existencia de instancias internacionales para dirimir confliclos. Pcro inás de londo, la guerra no era la única respuesta al atentado. Bien se pudo haher recurrido a tribunales internacionales. Recuérdese que eso hizo el gobierno de Nicaragua, responsabilizando a Estados Unidos de la muerte de miles de civiles. El tribunal de La Haya condenó entonces al gobierno estadounidense, aunque éste no reconoció la competencia de dicho tribunal'"

Ahora que la hurnanidad comienza un nuevo milenio, con promesas y expectativas de todo tipo, promovidas, por cierto, por el mundo occidental, no solvenlar política y pacíficamente el problema, ha sido una oportunidad perdida -además de mostrar el alto porcentaje de inelicacia, e hipocresía, de mucho del aclual lenguaje occidental.

Pero es una oportunidad perdida en otro sentido más primordial, más primigeniamente humano - y más utópico-, que es lo que ahora nos interesa recalcar. Sin duda, es hoy todavía utópico - "lo que no ha lugar"- pensar que Estados Unidos pueda someterse al veredicto de una instancia o tribunal internacional. Pero es todavía más utópico que Estados Unidos vuelva sobre sí mismo, analice su pasado, busque su verdad y sienta dolor, también paz, en el hecho de encontrarla, aunque eso le exija conversión. Por último, es utópico que busque y olirezca reconciliación y fraternidad, antes que cualquier otra cosa.

Plantear estas utoplas puede extrañar, pues en realidad son ou-lopia (lo que no ha lugar). Escribir sobre ello es más difícil que denunciar proféticamente -como hemos hecho-la insensibilidad ante el sufrimiento y la compasión, y la falta de voluntad de verdad. Pero es absolutamente necesario, pues con la utopía se formulan dos cosas esenciales para la humanidad. En primer lugar, el conlenido cle lo humano, aquello hacia lo que la humanidad debe tender, y según lo cual se

21. Antes Nicaragua había apelado a la Corte Mundial y al Consejo de Seguridad de Naciones Unidas. "En la actualidad, Estados Unidos es el único Estado que ha sido condenado por la Corte Mundial y ha vetado la resolución del Consejo de Seguridad" (que le lue contraria en la caso de Nicaragua), Noam Chomsky. op.cit. p. 5. 
medirá lo humano o inhumano del progreso. Y en segundo lugar, la esperanza de que lo humano es posible. Utopia (eu-topia) es lo bueno bajo ambos capítulos. Scgun eslo, valyamos a las "oporlunidades perdidas", y que nadie se asuste de que las lormulemos como posibilidades y exigencias, que surgen en un proéco de "conversión".

¿.Qué hubiesc ocurrido si cl Congreso y La Casa Blanca, animados y apoya(los por los gobiernos occidentales democráticos, por las universidades que ereen en la lihertad, la igualdad y la lraternidad, por las iglesias y las religiones yue creen en un Dios bueno, de déhiles y víctimas, por los movimientos humanistas. que creen en los derechos a la vida del ser humano, se hubiesen pregunliado por quéc tal horror, qué ha hecho ese país en sus dos siglos de existencia para concitar tal odio"? Esto es lo que de antiguo se ha llamado "exaınen de conciencia", considerado como cosa buena por conlesores y psiquiatras, en siluaciones de crisis de lass personals. i.Por qué lo que es hueno y humanizante para la persona no va ser hueno y humanizantc —debidannente historizado- para los pucblos?

¿Quć hubiese ocurrido si Estados Unidos hubiera abierto los ojos a su propia realidad y su corazón al dolor que ha infligido en este planeta? "Dolor de coraán" se llamaba a csto. Pero pareciera que cl sentir dolor es debilidad intolerable para una superpotencia, con lo cual queda aprisionada en el mal fundamental, que analizábamos en el primer punto: sin participar en el sulrimiento y en la compasión no hay humanidad.

¿Qué hubiesc ocumido si. unilatcral y precisamente, en esos inomentos de sulrir una agresión, hubiese puesto gestos de comprensión hacia los pueblos inusulmanes y de todo el tercer mundo, gestos de compasión y aprecio hacia sus gentes que llevan siglos de pobreza y sulrimicnto, gestos de intercambio de riquezas naturales y espirituales -y no la depredación de inaterias primas y la imposición de una pseudocultura? "Reparación" por el mal hecho, se decía antes. Esto humaniza. No la soberbia de quien se cree intocable física y moralmente.

¿Qué hubiese ocurrido si la primera palabra, sin quitar el dolor ni la búsqueda de justicia para los culpables, hubiese sido una invilación a la reconciliación? Así culmina el proceso de conversión: con la paz de volver a saberse humano y, sobre todo, con el gozo de saberse humanos unos con otros. la reconciliación, la mesia compartida.

Evidentemente no ha ocurrido así, ni sé si a alguien se le habrá pasado tal cosa por la imaginación. El poder nunca ha ayudado a la reconciliación. No la soberbia, sino la sencille $z$ y el abrazo cariñoso pueden acabar con la prepolencia, con querer bombardear y destruir más, con el "ganar" una guerra -inmensa desgracia, siempre, y más hoy, ésa de ganar una guerra, pues produce miles de muertos.

Lo ocurrido no llega a "oportunidad perdida", porque parece imposible. Pero no del todo. Ya hemos mencionados gestos ulópicos, de perdón y de reconcilia- 
ción. de parte de familiares de las víclimas. Desde Chalatenango, campesinos y campesinas han enviado cartas de solidaridad a sus amigos y hermanos de Estados Unidos, país del que, por una parte, recibieron destrucción, y por otra, mucha solidaridad. Es la locura del perdón dentro de Estados Unidos y de la reconciliación y el cariño que vienen de fuera.

Resistiéndome a aceplar que la oportunidad de algo bueno se perdió del Ixlo. poco después del 11 de septiembre escribí esta ficción utópica. "En El Salva(lor ha habido muchos II de sepliembre. más duraderos, crueles e injustos, igualmente indelensos. Manhattan empieza a entender a El Salvador, y a los indígenas de Guateınala. y a los aliricanos de Ruanda, Burundi y la República Democrática del Congo. Comienza a entender a los álabes y musulmanes de Irak, de Palestinil". Y a estas palabras añadi eslas otras todavía más utópicas, únicas - pienso- que. en definitiva, pueden salvar al imperio del norte. "Sin decirlo, quizás scílo intuyéndolo. empiezan a sentir que pertenecen a una gran lamilia, de sufrimiento y de compasión: la lamilia humana. Perlenecer al país más poderoso de lal ticrra hat perdido su encanto. Mejor es ser hermanos y hermanas".

Pcro, aunque absolutamente utópico, no se pucden desperdiciar de manera impune estas oportunidades - u olras más modestas- de humanización. Bien sathemos que para solucionar conllictos, o para imponer la voluntad propia, siempre sce usa del poder. Pero nunca. o rara vez. se quiere usar la lueiza - el poder- que procede del amor. Nunca sabremos lo que hubiera pasado si Estados Unidos hubiera seguido esic otro caınino utópico. Preferir pertenecer a la lamilia humana a ser los más poderosos, of recer reconciliación antes que venganza, apoyo a un pucblo pobre antes que destrucción, es utopia. pero es lo que humaniza y, a la larga. lo gue mina al terrorismo por dentro. En cualquier caso, lo peor que pucele pasar es que la humanidad ni siquiera intente dejarse guiar por los valores de lat utopía. dictamine que ese camino está totalmente descaltado y, en el fon(lo. que lo desprecic, porque liene otro camino mejor, el camnino del poder. El camino es posible, pero para ello hace lialta "voluntad de humanidad", más addecuadia cue la de "voluntad política", que no parece tener capacidad para cambiar las cosists. El clocumento de obispos antes cilado alirma y analiza su posibilidad:

Lo que se está gustando en la operación contra Alganistán scría suliciente para liberar a esa nación y a muchas otras del hambre, la miseria y la destrucción a que están somelidas, inaugurando relaciones de respelo y cooperación. de ayuda y solidaridad, y no agravando sulrimientos e implantando nuevals semillas de odio e incomprensiones.

No es la primera vez en la historia reciente que Estados Unidos se encuentra en una siluación militar que le cuestiona desde dentro. y que le pregunla, de moxlo simple, si quicre scr una nación y un puchlo humano o no. Clamorosamente ocurrió en Vieınam. Por cso nos preguntamos ahora qué hubiese ocunido si se hubiesen recordado las siguientes palabras de Martin Luther King durante la guerta de Vietnam: 
Estoy convencido que si queremos ubicarnos en el lado correcto de la revolución mundial, tenemos que emprender, como nación, una revolución radical de valores... que pronlo nos llevará a cuestionar la justicia y el equilibrio de muchas de nuesiras políticas del pasado y del presente... Una verdadera revolución de valores nos llevará a mirar con preocupación el enorme contraste entre la pobreza y la riqueza... Nos estamos confrontando a una tremenda urgencia... Hoy todavía nos queda una opción: la co-existencia no-violenta o la violenta aniquilación de todos.

\section{Qué Dios está en medio de la barbarie y del terrorismo}

Cuarta proposición. Los dioses, religiosos o seculares, están presentes en la barbarie y el terrorismo. El Dios de las religiones, ciertamente, el Dios abrahárnico, aunque puede ser usado de manera fanálica, está en lavor de la vida de todos y. en especial, de los débiles. Y la tradición cristiana añade que. por defender al débil de todo tipo de barbarie, el mismo Dios está crucilicado.

En la crisis actual se ha hablado mucho, de modo crítico, sobre Dios y religión. pero desde una perspectiva específica. De la misma manera que en una tragedia como el terremoto reaparece el problema de la teodicea (i.puede y quiere Dios impedir la tragedia?), en las guerras, donde estí en primer plano la voluntad huinana. reaparece el problema de la religión como generadora de fanalismo. Sobre esto queremos hacer unas breves rellexiones, desde la concepción bíblico-cristiana, pero alïrmando desde el principio que "dioses" hay muchos, en su versión "religiosa" y en su versión "secular", y que ambos estaban en Manhattan y en los cielos y en la tierra de Afganistán.

"No usar el nombre de Dios en vano" (segundo mandamiento). Hacerlo es costumbre inveterada, sobre todo en tiempos de guerra, de lo cual ya da testimonio el Antiguo Testamento, en sus inicios: en nombre de Jahvé se daba muerte a los sacerdoles de Baal. En liempos de cristiandad, los cruzados llevaban una cruz y ganaban indulgencias, que les facilitaban la salvación. A América Latina vinieron junlas cruz y espada. Guerras de religión y guerra sanla las hemos hecho durante milenios. Y aquí seguimos a Saramago.

Todavía ocurre en la actualidad con algunos grupos religiosos en orientc: "Estos aviones han sido enviados por Dios a destruir las torres", lo cual aterra al ser humano. pues se trata de dar muerte a otros seres humanos, y al creyente por hacer a Dios responsable último de esas muertes. Pero, desgraciadamente. cl segundo mandamiento no se viola sólo en oriente. En Europa, más secularizada, no se suele introducir a Dios, por nombre, en asunto de guerras (lo cual no (juiere decir que no se invoque a dioses seculares). Pero en Estados Unidos, Bush padre oró la noche antes de bombardear lrak (lo que dejó más de 100.000 muertos). God bless you es el final obligado de muchos discursos presidenciales, uunque hayan tenido que mentir sobre cosas muy graves: los derechos humanos, 
la guerra, la vida y la muerte. También jerarcas eclesiásticos han bendecido tropas, aviones y helicópteros, en Estados Unidos y aquí entre nosotros, en El Salvador - y la verdad es que no acabamos de entender qué se pretende con ello. En vano hemos tomado - y seguimos tomando- el nombre de Dios.

"No servir a los idolos". En esta guerra tampoco está ausente Dios a la manera de ídolo. Y sobre esto digamos dos cosas que nos parecen importantes.

a) Los males de invocar a las divinidades seculares. Nadie puede librarse de algún "dios". Todos somos religiosos, estamos remitidos a algo último, aunque de formas distintas. Jesús lo decía con su sabiduría acostumbrada: "hay muchos señores y ustedes tienen que elegir a cuál de ellos quieren servir". Y les ponía un ejemplo que, por lo menos en nuestro occidente materialista y vividor (religioso o agnós(ico), pone el dedo en la llaga: "no pueden servir a Dios y al dinero"22. Dioses hay muchos, y suelen estar presentes en las guerras, precisamente, porque en éstas están en juego muchas cosas "últimas".

A veces no se emprenden las guerras en nombre de dioses "religiosos", sino en nombre de dioses "seculares", verdaderos ídolos: oro, peiróleo, uranio, coltán, espacios esıratégicos (El Salvador fue considerado como dios - algo último- por ser el "patio trasero" de Estados Unidos). Pero no hay que engañarse, exigen lo mismo que los otros dioses. Las formas externas del culto pueden cambiar: unas inás abiertamente fanáticas (hasta el suicidio); otras, más pulidas, pero igualmente empecinadas y decididas, si es necesario, a hacer uso de la mayor crueldad, para defender a occidente, y sobre todo el bienestar y la libertad propia, de modo que nada amenace ni moleste.

Ambos tipos de dioses, religiosos y seculares, tienen mucho en común. Veámoslo desde los dioses seculares, pues esto se critica más obviamente a los dioses religiosos. Son intocables. "Yo denuncio sobre todo la absolutización de la riqueza... como un absoluto intocable. $¡ Y$ ay del que toque ese alambre de alta Iensión! Se quema", decía Monseñor Romero (Homilía del 12 de agosto de 1979). Se presentan como aigo último y no necesitan justificación. Baste recordar el business is business, formulación altamente teologal. Y sobre todo generan victimas. Los ídolos históricos, decía Monseñor Romero, como el Dios Moloch, exigen víctiInas para subsistir (Cuana Carta Pastoral, 6 de agosto, 1979). En nuestros días, los ídolos generan víctimas de manera directa en las torres o en Afganistán, y de manera directa en vastas regiones del planeta, Africa, Pakistán, India... Hace poco ocurría de forma masiva en Centro y Sudamérica, pues dioses eran, "ídolos", la acumulación del capilal y la docirina de seguridad nacional.

22. En sociedades secularizadas. la alternativa al verdadero Dios no liene por quê ser en sí mismo algo malo. sino bueno. Puede formularse como "lo humano". la "instauración de la justicia", etc. En estos casos. Dios no liene por qué ser excluyente de esas "divinidades", al menos en teoria, sino que ambos pueden convergir. 
Desde esta perspectiva. la idolatría, religiosa o secular, se verifica en si se violan o no los mandamientos que defienden la vida de los seres humanos. "No depredar" (séptimo mandamiento) siempre ha sido problema mayor de imperios y potencias: quedarse con lo de otros: oro, petróleo, uranio, coltán, espacios ricos en inaterias primas o valor estratégico. También ha sido violado el quinto mandamicnto "no matar", o para mantener la depredación o para defenderse de ella o para exicrminar o aterrorizar a los supervivientes. Por último, ha sido violado el "no mentir" (oclavo mandamiento) para encubrir, justificar, hacer pasar desapercibido lo anterior, cl roho y la muerte.

b) Los peligros de invocar a las divinidades religiosas. Las religiones monoteístas, con un tronco coınún en Abraham (un único Dios: Yahvé, el Padre de Jesús, Alá), de libro (una única verdad: Antiguo Testamento, Nucvo Testamen(1). Corán) y de elección (un único pucblo elegido) pueden generar graves peligros, al mal usar a Dios. El monoteísmo puede provocar exclusivismo e intolerancia, por una parte, y proselitismo, que llega a privar de libertad, por otra; el ser religión de libro, algo fijado e intocable, puede justificar el lundamentalismo, aunque puede someterse a la legítima ilustración de la razón; la elección puede gencrar conciencia de superioridad y de tener derechos sobre los demás, aunque, tanto en el judaísmo y el cristianismo, ciertamente, existen autocorrectivos para cvilar este peligro, al denunciar una comprensión mecánica de la salvación, que proviene de la elección"?

Estos peligros son reales en las religiones, pero hay que insistir en que no son monopolio inherente a la comprensión "rcligiosa" de Dios. El monoteísmo, en lo que tiene de excluyente y belicoso, está muy presente en las palabras de Bush: "o con nosotros o con los terroristas". La conciencia de elección, y sus peligros, está presente en la políica exterior y militar de Estados Unidos casi desde sus orígenes, y en eso nos queremos delener. Ya hernos aludido al "destino maniliesto" que invoca. En 190), el senador de Indiana Albert Beveridge lo lormulaba Iodavía en lenguaje explícitamente religioso. Reliriéndose a Dios decía que

nos ha dado el don de gobernar para que demos un gobierno a los pucblos sal vajes y seniles. Sin esta luerza nuesira, el mundo recaería en la barbaric y en la noche... Dios ha designado al pucblo norteamericano como su nación clegida para comenzar la regeneración del mundo ${ }^{24}$.

23. Bien entendida. la elección de Israel era para la misión. el bien de olros, no para provecho propio. Tampoco era algo exclusivo de Israel, como to repiten los prolelas. Amós relaliviza la clección, universalizando la acción de Dios: "¿No hice yo subir a Isracl del país de Egipto. como a los filisteos de Kaltor y a los arameos de Quir?" (Am 9. 7). Y Juan Bautista denuncia la autocomplacencia de los judíos: "Les digo (jue Dios puede hacer de estas piedras hijos de Ahraham" (Lc 3, 8).

24. Tomado de J. I. González. Faus. op. cit. 
La conciencia de "elección" sigue presente en la derecha estadounidense, aunque no se formule religiosamente. En 1997, Madeleine Albright hablaba así sobrc la elección, el destino manifiesto:

Nosolros los norleamericanos tenemos una ventaja sobre las olras naciones: sabemos quiénes somos y qué creemos. Somos constructores. Nuestra responsabilidad no es actuar como prisioneros de la historia, sino hacer historia... Tenemos una razón de ser, más la fe en que, si somos fieles a nuestros principios, triunlaremos ${ }^{25}$.

"Amar con rodo el corazón al Dios de la vida" (traducción libre del primer mandaunicnto). Según la tradición bíblico-cristiana, en nombre de Dios sólo se puede generar vida. No quila esto que no haya conflictos en la historia, ni que el ser humano no tenga (o pueda) ponerse ante Dios, en esos momentos. Pero lo que hay que recalcar es que Dios está en favor de la vida de lodos los seres humanos, y se declara defensor de la vida de pobres y débiles.

Dios no ve, en primer lugar, a seres humanos "religiosos", afiliados a una u oura rcligión, o agnósticos o atcos, sino que ve, ante todo, a "seres humanos", sufrientes y esperanzados, oprimidos muchas veces, liberadores otras. Y lo que quiere es que en este mundo haya vida. Historiadores de las religiones debatirán las diferencias en la formulación de estas intuiciones. cotejarán lextos, los del Antiguo Testamento, los del Nuevo Testamento, los del Corán. Encontrarán cosas comunes, a veces al pie de la letra. Pero más allá de la letra, podrán encontrar —eso csperamos - la realidad de un Dios, que es "Padre de huérfanos y viudas", Yahvé; "buena noticia para los pobres", el Padre de Jesús; "compasivo y misericordioso", Alá.

Si así es Dios, así deben ser los seres humanos, que explicitan su identidad "religiosamente", abrahámicamente. En nuestra opinión, más allá de aceptar fomulaciones y creencias concretas - a lo que son propensas las religiones-, hay que hurgar en el corazón hurnano para ver si allí resuenan esas palabras de compasión y misericordia hacia los débiles, y si en el acoger ese resonar encuentran todos el camino para ser humanos. Eso no quita que exista diversidad de cultos y oraciones, diversas escrituras y lugares santos. Sólo recalca que lo verdaderamente santo está en la compasión y la misericordia hacia el débil. Y esa es la verdadera línea divisoria en el mundo. No las religiones y su diversidad, sino la Iniscricordia al débil (para los creyentes la esencia de Dios), por una parte, y la riqueza para uno mismo (el dios que produce víctimas), la arrogancia y la prepotencia, por otra.

$Y$ es que la religión, en último término, remite al ser humano. Este puede comprenderla y usarla de varios modos: fundamentalista, integrista, fanática y

25. Tomado de ibid. 
agresivamente, pero lambién servicial, compasiva, místicamente, abierta siempre al más de la lamilia humana. Y de igual modo, ese mismo ser humano puede usar bien la democracia, pero puede des-democratizar la realidad, reclamar la libertad pilra sí mismo, negándosela o otro; ignorando de modo paladino la igualdad de lodos los seres humanos; haciendo mofa de la fraternidad. A los males del lundamentalismo y del lanatismo rcligioso, la democracia opone la tolerancia -y hien cstá. Pero de la tolerancia a la indiferencia, al desentendimiento de lo humano, en el tercer mundo, a declararlo no-existente, como pasa con Africa, hay sólo un paso. Tolerancia, sí. Pero en nuestro mundo hay cosas intolerables, y no se puede invocar - aunque no se haga de forma explícita, por supuesto- la tolerancia para hacerlas tolerables.

\section{***}

Según la lé cristiana, en nombre de Dios no se puede causar víctimas, sino quc hay que defenderlas. Piénsese en el cristianismo de Mons. Romero, Helder Caınara, Leonidas Proaño, Pedro Casaldáliga, Samuel Ruiz, por nombrar sólo ohispos latinoamericanos conocidos.

Y, para terminar, ese Dios estuvo presente en una víctima, Jesús crucificado. No envió bombas contra nadie, sino que cayeron sobre él, como siguen cayendo en estos días sobre mujeres, niños y ancianos indefensos. Extraño Dios, ciertamentc. Pero entrañable. En su nombre no se puede matar al hermano, sino sólo lar vida. Y es capaz de dar esperanza - y en eso nos separamos de Saramago. ¿Ulopia? Ciertamente. Pero jay del mundo, de los países, de los pueblos sin utopía! Y así comenzamos la última rellexión.

\section{La redención de todos los terrorismos}

Quinta proposición. Según la tradición bíblico-cristiana para superar el mal, la barbaric y el terrorismo hay que combatirlos desde fuera, pero también desde dentro. Así se opera la liberación y la redención.

Aunque es lo que da título al artículo, vamos a tratarlo de forma muy breve para terminar. El terrorismo, en cualquiera de sus formas, es injusto, cruel y repugnante. De ahí que la gran pregunta es cómo acabar con él, cómo erradicarlo, cs Jccir, quitarle raíces. Sobre esto quisiera decir dos cosas, que se relacionan, pero que no son lo mismo.

La primera es que hay que combatir el terrorismo "desde fuera", con todos los medios lícitos y eficaces: construir estructuras de justicia, fomentar una culIura de paz. evitar olensas que exacerban, más las diligencias legítimas policiales, jurídicas... Esto es obvio y legítimo - y difícil-, pero queremos insistir en que es una lucha "desde fuera", que ojalá ayude a "superar" el terrorismo. La 
ségunda es que, además, hay que "redimirlo", y para ello no basta luchar contra él "desde fuera". sino que hay que combatirlo "desde dentro".

Esto esı́a en la entraña de la tradición bíblico-cristiana. Hay que quitar el pecado del mundo. pero también hay que redimirlo. y para ello. hay que cargar con él. dejar que descargue su poder sobre uno mismo. Eso es lo que se dice del siervo de Yahvé. Su vida y misión es instaurar el derecho y la justicia, scr luz de las gentes. pero termina como siervo sufriente, cargando con el peso de la menlira y la injusticia. destruido por el pecado, y así trae salvación. Y lo mismo se clice de Cristo en el Nuevo Testamento: evangelizador y profela en vida, termina crucilicado: en la cruz cargó con el peso del pecado, éste desahogó su poder y por así đlecirlo, quedó como sin fuerza para producir más daño. Desde esta perspectiva. la resurrección signilica no sólo el triunlo de la persona de Cristo, sino que el cargar con el peso del mal, la cruz, trae salvación.

Ellacuría, quien dedicó su vida a combatir el pecado (injusticia, mentira, violencia. (errorismo...) "desde fuera", con todas sus fuerza y con todas las capacidades de la UCA, estaba también convencido de que eso no basta. No siolo hay que "encargarse de la realidad", a través de una praxis salvífica, sino que hay que "cargar con la realidad", con su peso demoledor. Esto no era en él lenguaje espiritualista, ni sólo religioso, y, ciertamente, no masoquista, sino honda convicción. A la injusticia y a la violencia hay que "redimirlas", vencerlas desde dentro. aunque esto lleve al propio sufrimiento y aun a la muerte.

El 19 de septiembre de 1989, en un discurso altanente político, en presencia del Presidente Carlos Arias de Costa Rica y Alfredo Cristiani de El Salvador, dijo que el trabajo por la paz exigía inmensos sacrificios, y añadió, de forma inesperada, lo siguiente:

Mucho ha sido el dolor y mucha la sangre derramada, pero ya el clásico teologoumenon de nulla redemptio sine efussione sanguinis nos viene a recordar que la salvación y la liberación de los pueblos pasa por muy dolorosos sacriticios.

Lo mismo vale para la lucha contra la barbaric y el terrorismo. Para erradicarlo, "redimirlo", hay que estar en la realidad de la injusticia que lo ha provocado, en último término. dejándose afectar por ella, luchando contra ella, aceptando que revierta su luerza contra quien lo quiere eliminar. Hay que denunciar la inhumanidad de todos los terrorismos, estar dispuestos a la reconciliación y el perdón, aunque eso tenga altos costos personales y prolesionales. Hay que csiar en el dolor que producen todos los lerrorismos. Hay que ser reales, fieles a la encarnación hasta el linal. Se redime, luchando contra el pecado y, al mismo tiempo, cslando en la realidad de pecado, idea poco -o nada- considerada.

Para el cristiano, la última justificación para concebir así la redención está en el mismo Dios. Creador, configurador de este mundo, presente en el quehacer 
de Jesús. sí. Pero, simultáneamente, presente, doliente en la cruz. Ese Dios estuvo presente en una víctima. Jesús crucificado. En su nombre no se puede matar al hermano, sino sólo dar vida.

No es lácil luchar contra el mal, la injusticia, la mentira, la barbarie y el terrorismo, "desde fuera". Pero mucho más difícil es luchar, simultáneamente, contra ello "desde Jentro". Lo primero es absolutamente necesario, pero, con todo, no es suliciente, como lo muestra la historia. Se necesita también luchar "desde dentro". Ese paso sumamente difícil es milagro de la gracia y expresión Jel inayor arnor.

Eso es lo que han hecho los mártires, Monseñor Romero, los de la UCA y muchos otros. Luchar "desde fuera" con todas sus capacidades al servicio de la vida, la verdad, la justicia y la paz. Y luchar "desde dentro", arriesgar sus vidas -hasta darlas - en esa tarea. Verdaderamente, es justo y necesario darles gracias.

San Salvador XII Aniversario de los mártires de la UCA. 